\title{
Optical absorption enhancement in sensitized ZnO nanorods for solar cells
}

\author{
Aumento de la Absorción Óptica en \\ Nanovarillas de ZnO Sensibilizadas \\ para Celdas Solares
}

\author{
Carlos Javier Pereyra ${ }^{1}$, Florencia Ferrer ${ }^{1}$, Carmela Gómez ${ }^{1}$, \\ Lucía Campo $^{1}$, Ricardo Enrique Marotti ${ }^{1}$, Francisco Martin ${ }^{2}$, \\ Dietmar Leinen ${ }^{2}$, José Ramos-Barrado ${ }^{2}$, \\ Enrique Ariel Dalchiele ${ }^{1}$
}

\footnotetext{
${ }^{1}$ Instituto de Física \& CINQUIFIMA, Facultad de Ingeniería, Universidad de la República, Julio Herrera y Reissig 565 CP: 11300, Montevideo, Uruguay. e-mail: jpereyra@ fing.edu.uy

${ }^{2}$ Laboratorio de Materiales y Superficies (Unidad Asociada al CSIC), Dptos. de Física Aplicada \& Ingeniería Química, Universidad de Málaga, Málaga, Spain.
}

\begin{abstract}
RESUMEN
Se estudiaron las Propiedades Ópticas (PO) de Nanovarillas (NV) de ZnO sensibilizadas con diferentes semiconductores en nanoestructuras núcleo-corteza, comparándolas con las PO de NV de ZnO. Las medidas experimentales de Transmitancia y Reflectancia Difusa muestran un incremento en la absorción de luz en el espectro solar y la aparición de nuevos bordes de absorción (BA). Las medidas se compararon con simulaciones numéricas basadas en Aproximación de Medio Efectivo (Bruggeman). Las simulaciones corresponden con las medidas reproduciendo la dependencia con el contenido de sensibilizante. Para CdTe se observa un aumento de la absorción con la cantidad del sensibilizante, siendo los cambios mayores para iguales cambios en las fracciones de llenado respecto al CdS. Las mediciones experimentales muestran corrimientos en las posiciones de los BA entre $2.34 \mathrm{eV}$ y $2.66 \mathrm{eV}$ para $\mathrm{CdS}$. Estos corrimientos no pueden explicarse sólo por cambios en el contenido de sensibilizante o por los efectos de confinamiento en las nanoestructuras. Similar es el comportamiento del BA de muestras sensibilizadas con CdTe que se ubica entre $1.31 \mathrm{eV}$ y $1.36 \mathrm{eV}$, analizadas por Transmitancia, mientras que para las mismas muestras este BA se encuentra en $1.57 \mathrm{eV}$ y $1.49 \mathrm{eV}$, respectivamente, según el método de Kubelka-Munk de la Reflectancia. Además se observa el BA de la banda split-off en $2.55 \mathrm{eV}$ y $2.28 \mathrm{eV}$. Estos corrimientos pueden asociarse a un incremento de la absorción sub-bandgap debido al aumento del recorrido libre medio de la luz en la estructura.
\end{abstract}

Palabras clave: Nanoestructuras, $\mathrm{ZnO}$, Nanohilos, Celdas Solares

\section{ABSTRACT}

The Optical Properties of $\mathrm{ZnO}$ Nanorods (NR) sensitized with different semiconductors in Core-Shell nanostructures were studied, comparing them with those of bare $\mathrm{ZnO}$ NR. Experimental measurements of Transmittance and Diffuse Reflectance show an increased light absorption at the solar spectrum and the appearances of new absorption edges (AE). The measurements are compared with numerical simulations based on Bruggeman Effective Medium Approximation. An increased absorption with the sensitizer content is observed. For similar changes in filling fractions, CdTe presents higher changes in absorption than CdS. Shifts in the AE are observed experimentally (e.g. between $2.34 \mathrm{eV}$ and $2.66 \mathrm{eV}$ for $\mathrm{CdS}$ ). These shifts cannot be assigned to sensitizer content or confinement effects. A similar behaviour is observed for CdTe in which the AE measured by transmittance is between $1.31 \mathrm{eV}$ and $1.36 \mathrm{eV}$, while the one obtained from Kubelka-Munk analysis of reflectance is, for the same samples, $1.57 \mathrm{eV}$ and $1.49 \mathrm{eV}$, respectively. Moreover, the split-off AE is also observed at $2.55 \mathrm{eV}$ and $2.28 \mathrm{eV}$. The observed large red-shifts could be associated with an enhancement of the subbandgap absorption due to an increase in the light free path at the core-shell nanostructure. 
Keywords: Nanostructures, $\mathrm{ZnO}$, Nanowires, Solar Cells.

\section{INTRODUCTION}

The use of nanorods (NR) in photovoltaic solar cells may increase their efficiency by decoupling light propagation and carrier separation into orthogonal directions $[1,2]$. One of the most promising candidates for these $\mathrm{NR}$ based solar cells is $\mathrm{ZnO}$. $\mathrm{ZnO}$ is a transparent semiconductor oxide with a usually reported bandgap energy (BE) of 3.2-3.4 eV [ [3] . In order to achieve high visible absorption another semiconductor must be incorporated as a sensitizer in a NR core-shell array. For this application $\mathrm{ZnO}$ NR acts as the core and the sensitizer form a Nanoparticles (NP) shell surrounding the NR. The sensitizer used will be determinant in the posterior optical performance of the material; here the most important candidates are $\mathrm{CdS}$ or $\mathrm{CdTe}[4, \underline{5}]$. Previously reported $\mathrm{ZnO} / \mathrm{CdS}$ NR core-shell array sensitized by Successive Ion Layer Adsorption Reaction (SILAR) shown an increased absorption in the visible [ $\underline{6}-\underline{8}]$. Moreover, a dependence in the absorption edge position was observed for these samples with the NP size and CdS content in the samples [ $\underline{6}-\underline{-}]$. CdTe is an II-VI semiconductor alloy with a BE between 1.47-1.53 eV [9-13] very close to the optimal BE for photovoltaic applications. Moreover, is possible to observe the split-off $\mathrm{AE}$ ca. $2.5 \mathrm{eV}$ due to the spin-orbit splitting (ca. $0.95 \mathrm{eV})$ [12-14].

This work studies the optical properties of CdS and CdTe sensitized ZnO NR samples. It is focused on the visible absorption enhancement due to the sensitizations and shows how the CdTe sensitized samples present a red-shift in the $\mathrm{BE}$ as was observed in CdS sensitizer ones [ $\underline{6}-\underline{8}]$.

\section{MATERIALS \& METHODS}

\subsection{Experiment}

The $\mathrm{ZnO}$ NR sensitized with $\mathrm{CdS}$ and CdTe samples were prepared by a two stages deposition procedure. In the first stage $\mathrm{ZnO} \mathrm{NR}$ were grown on a fluorine doped tin oxide (FTO)-glass substrate by potentiostatic electrodeposition in a three-electrode cell [6-8]. The sensitization stage used the previously deposited $\mathrm{ZnO}$ $\mathrm{NR}$ as a substrate for the deposition of $\mathrm{CdS}$ and CdTe. CdS was deposited by spin coating assisted SILAR from $50 \mathrm{mM} \mathrm{Cd}\left(\mathrm{NO}_{3}\right)_{2}$ and $50 \mathrm{mM} \mathrm{Na} \mathrm{Na}_{2} \mathrm{~S}$ aqueous solutions [6,8]. On the other hand CdTe NP were electrodeposited from a $\mathrm{CdSO}_{4}+\mathrm{K}_{2} \mathrm{TeO}_{3}+\mathrm{NTA}$ bath at $75^{\circ} \mathrm{C}$. The morphology of these samples was studied using a JEOL JSM/5900 LV scanning electron microscopy (SEM). X-ray diffraction (XRD) was measured with a Philips PW1840 diffractometer $\left(\lambda_{\mathrm{Cu} K \alpha}=1.5406 \AA\right)$.UV-Visible optical properties were studied by transmittance $(T(\lambda))$ and diffuse reflectance $\left(\mathrm{R}_{\text {diff }}(\lambda)\right)$ measurements. For $T(\lambda)$ a $1000 \mathrm{~W}$ Oriel 6271 Xe lamp, a chopper (SRS SR540) and an Oriel 77250 monochromator were used. The transmitted light was detected with an UDT 11-09-001-1 (100 $\mathrm{mm}^{2}$ wide area UV enhanced unbiased Si detector) for the visible region, or a Newport 71616 (3 mm thermoelectrical cooled InGaAs detector) for the IR region. An SRS SR530 lock-in amplifier extracted the signal from the detector. Since the bare substrate produces interference (which is not observed when the $\mathrm{ZnO}$ NRs are already grown), the lamp was used as a reference [15]. For samples with very low $T(\lambda), R_{\text {diff }}(\lambda)$ was measured with an Ocean Optics (OO) ISP-REF integrating sphere coupled (by a $100 \mu \mathrm{m}$ core diameter fiber acting as input slit) to an OO S2000 spectrometer with a Sony ILX511 linear CCD array. For these $\mathrm{R}_{\mathrm{diff}}(\lambda)$ measurements an OO WS-1 reflectance standard was used as reference [8].

\subsection{Theory}

The Optical Absorption Enhancement of these $\mathrm{ZnO}$ NRs Core-Shell arrays was interpreted by the comparison of the experimental data with the results of numerical simulations based on the effective medium approximation (EMA) for ideally mixtures of $\mathrm{ZnO}$ NRs with NP of the sensitizer. The simulations were based on Bruggeman approximation. Here the effective medium acts as the matrix where the two materials (i.e. $\mathrm{ZnO}$ and $\mathrm{CdS}$ or $\mathrm{CdTe}$ ) are considered as inclusions. The complex dielectric constant of the composite material $\left(\varepsilon_{\text {eff }}\right)$ could be calculated from the dielectric constant of each one of the inclusions $\varepsilon_{\mathrm{i}}[\underline{16}]$.

$$
0=\sum_{i=C, S} f_{i} \frac{\left(\varepsilon_{i}-\varepsilon_{e f f}\right)}{\varepsilon_{e f f}+\left(\varepsilon_{i}-\varepsilon_{e f f}\right) L_{i}}
$$

where $\mathrm{i}=\mathrm{C}, \mathrm{S}$ are for the core $(\mathrm{C})$ and sensitizer $(\mathrm{S})$ material respectively and $\mathrm{L}_{\mathrm{i}}$ are the depolarization factors of each inclusion. The relative concentration of each inclusion is introduced in the simulations varying the values of the volumetric filling factors, i.e. the parameter $f_{i}$ in eq. (1). As the samples under studied are formed by the mixture of two materials then $f_{C}+f_{S}=1$. Thus, in the simulations, the only independent 
parameter was $\mathrm{f}_{\mathrm{S}}[\underline{6}, \underline{8}, \underline{16}]$. The depolarization factors depend on the shape of the inclusions and the direction of propagation of the light beam. $\mathrm{L}=1 / 3$ for spherical inclusions and $\mathrm{L}=1 / 2$ for cylindrical inclusions in the plane perpendicular to the axis of the cylinder. Previous results showed a small dependency on the Transmittance spectra with the depolarization factors $[\underline{6}, \underline{8}]$. In this work the depolarization factors were chosen to be $L_{C}=1 / 2$ for the $\mathrm{ZnO} N R$ core and $\mathrm{L}_{S}=1 / 3$ for the spherical sensitizer inclusions. The dielectric constant of $\mathrm{ZnO}, \mathrm{CdS}$ and CdTe were obtained from tabulated data $[\underline{13}, \underline{17}, \underline{18}]$. The random orientations of the $\mathrm{ZnO} \mathrm{NR}$ arrays were ignored. This is justified because of the theoretically desired geometry in which light travels along the axis of the nanorods [1]. Also, dispersions and scattering effects were neglected, then effects like refraction index matching and the formation of antireflective coatings are not expected in the simulations. Although this could lead to important discrepancies between sample measurements and simulation results, the purpose of the simulations is to account only for the filling factor dependency on the optical properties, particularly the shape of the spectra under study. The results of the simulations cannot be directly associated with the experimental results since the typically size of the NRs are of the order of the wavelength [16].

The Transmittance spectra $(\mathrm{T}(\lambda))$ was calculated from $\varepsilon_{\mathrm{eff}}[19]$ and its dependence on the filling factor was study varying $\mathrm{f}_{\mathrm{S}}$ from $0 \%$ (pure $\mathrm{ZnO}$ ) to $100 \%$ (pure $\mathrm{CdS}$ or $\mathrm{CdTe}$ ). The film thickness used was $1 \mu \mathrm{m}$, according with previously reported typical lengths of the $\mathrm{ZnO}$ NR arrays $[\underline{6}-\underline{8}, \underline{20}]$.

\section{RESULTS AND DISCUSSION}

\subsection{Morphological Study}

Figure 1 shows different SEM images of the ZnO Nanorod CdTe nanoparticle core-shell arrays. Figure 1(a) shows a bare $\mathrm{ZnO} \mathrm{NR}$ array before the sensitization stage; is possibly to see the smooth and regular surface of the NR with defined hexagonal crystal habit. In Figure 1(b), (c) ZnO/CdTe NR array are shown, note the smooth surface of the $\mathrm{ZnO}$ nanorod in comparison with the rough surface of the CdTe shells. Also, in Figure 1(c) it is also possible to see a detached CdTe shell. Typical measured radius of the NR was about $700 \mathrm{~nm}$ and shell thickness of 400 to $450 \mathrm{~nm}$. Moreover, in the centre of Figure 1(c) is clearly visible a $\mathrm{ZnO}$ nanorod with the CdTe nanoparticle shell surrounding it.

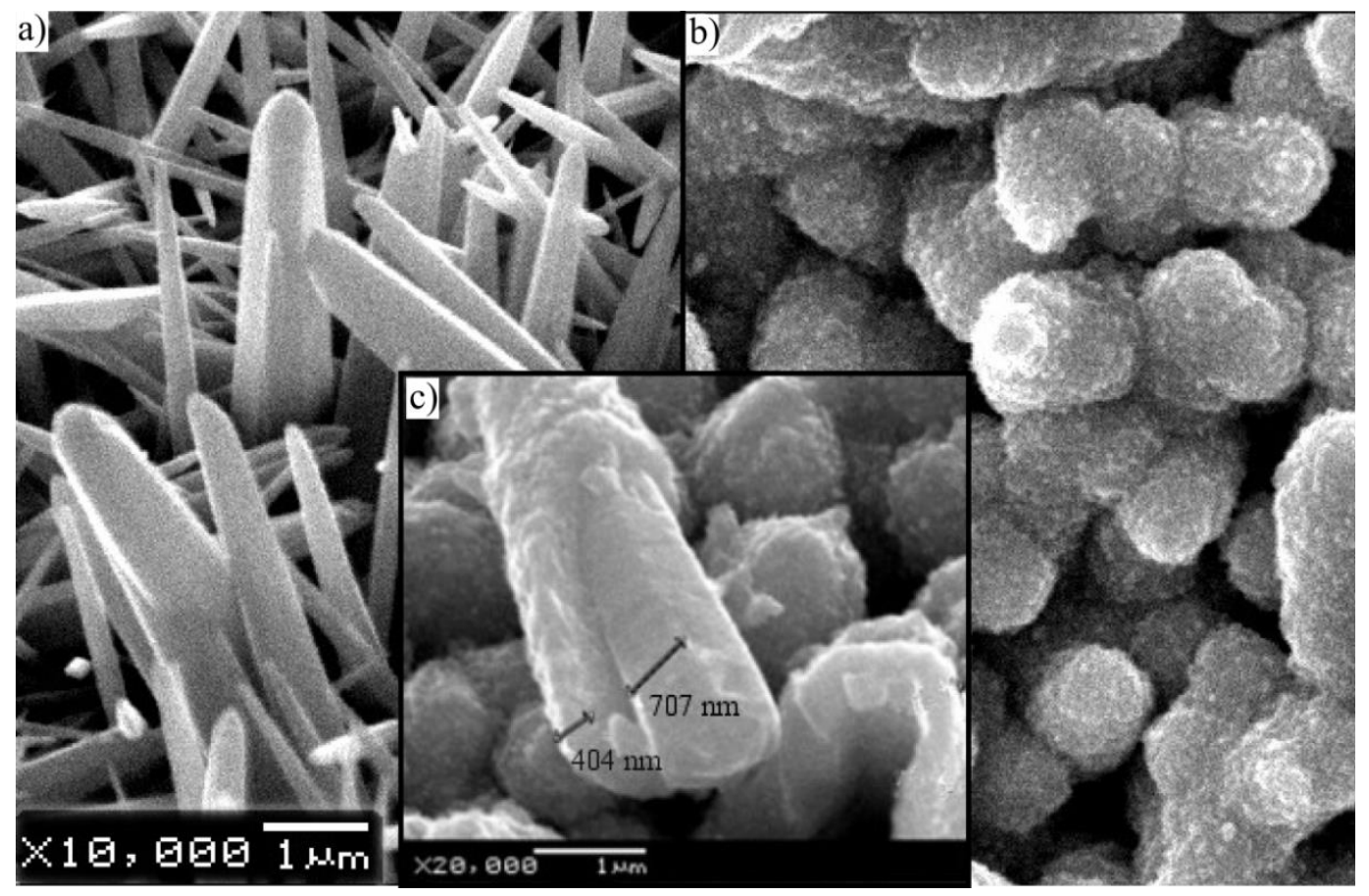

Figure 1: SEM images of (a) $\mathrm{ZnO}$ bare substrate, (b) $\mathrm{ZnO} / \mathrm{CdTe} \mathrm{NR}$ arrays and (c) magnified capture of $\mathrm{ZnO} / \mathrm{CdTe} \mathrm{NR}$ array.

\subsection{Numerical Simulations and Application Range.}

Figure 2 shows the calculated transmittance spectra for $\mathrm{f}_{\mathrm{S}}$ varying from $0 \%$ to $70 \%$. For the $0 \%$ content 
(pure $\mathrm{ZnO}$ ) only one feature is clearly seen. This feature is associated with the $\mathrm{ZnO}$ absorption edge located at $3.22 \mathrm{eV}$ (ca. $385 \mathrm{~nm})$. As the content of sensitizer (CdS or CdTe) is increased another feature appears and becomes more noticeable at higher $\mathrm{CdS}(\mathrm{CdTe})$ concentration. This new feature is associated with the $\mathrm{CdS}$ (CdTe) absorption edge located ca. $2.34 \mathrm{eV}$ for $\mathrm{CdS}$ sensitizer and $1.46 \mathrm{eV}$ for CdTe.

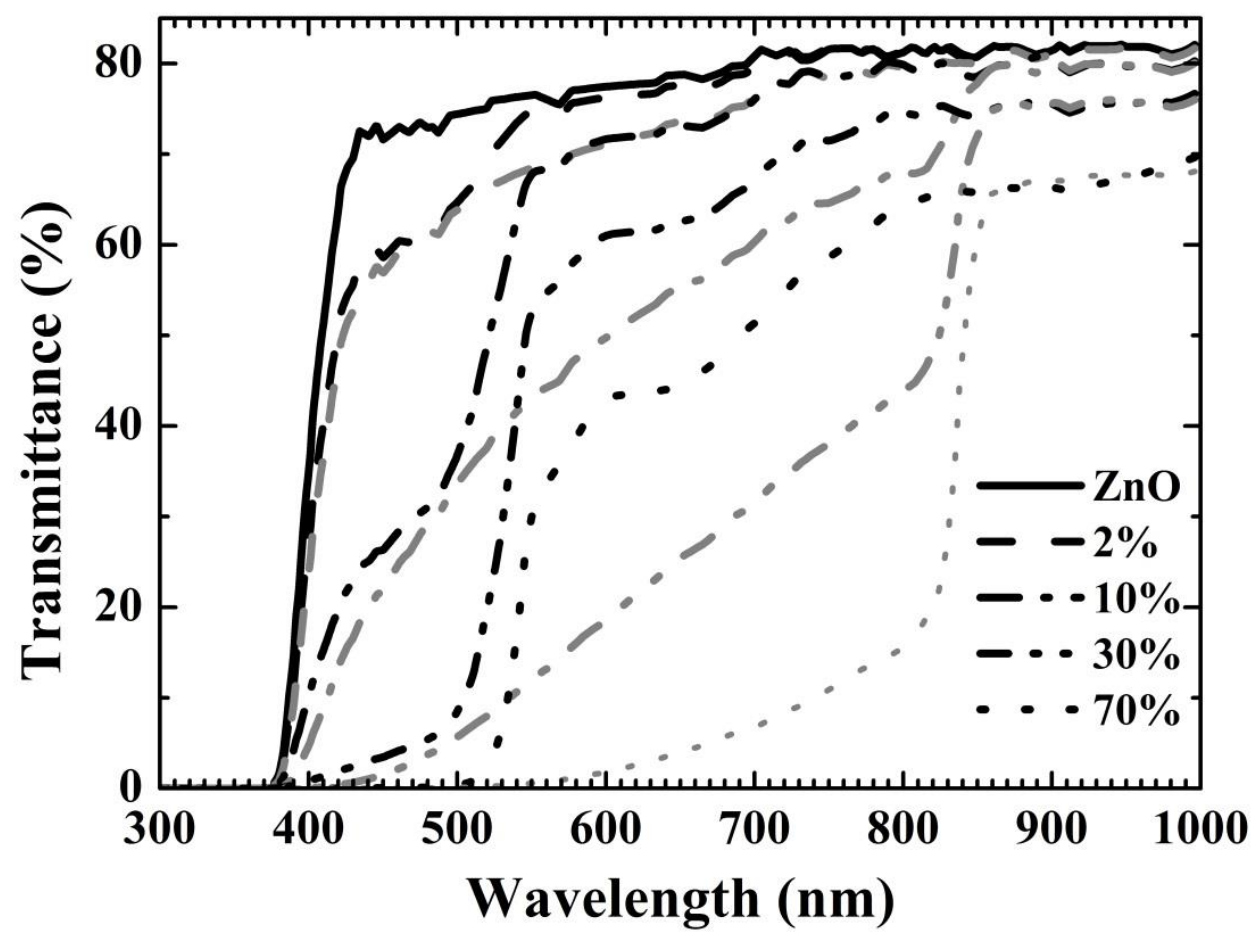

Figure 2: Calculated transmittance spectra of simulated $\mathrm{ZnO} / \mathrm{CdS}$ core-shell array (black curves) and $\mathrm{ZnO} / \mathrm{CdTe}$ (gray curves) varying the filling factor for $0 \%$ continuous line, $2 \%$ dashed curve, $10 \%$ dot dashed curve, $30 \%$ double dotted dashed and $70 \%$ dotted curve.

Figure 2 also shows a diminution of the transmittance when increasing $\mathrm{f}_{\mathrm{S}}$ for both sensitizers. This diminution represents an absorption enhancement in the spectral region between 400 and $850 \mathrm{~nm}$. For both sensitizers the relative absorption enhancement is larger for small values of $f_{S}$ than for higher $f_{S}$ values. Moreover, for the same $\mathrm{f}_{\mathrm{S}}$ changes a smaller enhancement is observed for CdS sensitization than for CdTe. The simulations correspond with the measurements reproducing the dependencies with the sensitizer content and the appearance of the absorption edges of each material, this confirms that $\mathrm{ZnO}$ and sensitizers are spatially apart $[\underline{6}, \underline{8}]$.

However the previous correspondence cannot be used as a way of trying to fit the experimental results due to the validity of the effective medium approximation. In effect, for the correct applicability of the present model the size of the inclusions should be smaller than the wavelength of the light [16]. In fact, for each wavelength there is a large size limit which, depending on the accepted tolerance, would be typically on the order of several tens to more than $100 \mathrm{~nm}$ [21], as there are also a small size limit and filling fractions limits. However, beyond these values the effective medium approximation could be used if certain high order corrections are included in eq. (1) [17]. For this reason the present simulation may not be directly used to fit results of the optical properties of the present samples, as the sizes of some of the NR are higher than that (see Fig. 1). But smaller size ZnO NR can be obtained with the use of seed layers for control of their diameter obtaining NR with sizes below that large size limit [22].

Moreover Fig. 1 also shows that there is an empty region (filled with air) between either the bare NR (or the core-shell sensitized ones). Therefore a more complete model should require the introduction of a third phase (air, with unity refraction index) in the effective medium approximation. This will not be considered for reducing the free parameters of the model to just one (i.e., $f_{S}$ with $f_{C}=1-f_{S}$ ). The empty region would contribute in reducing the effective constants of the composite nanomaterials in porous materials. Eventually Lorentz-Lorenz approximation should be used instead of Bruggeman Eq. (1) [16] but a 
new parameter related to the porosity should be introduced [23]. Therefore, the choice of the correct solution for the corresponding equation will more complicated [24]. Moreover a graded refraction index or multilayer model would be required, as it is seen in Fig. 1c, the air filling fraction may depend on the sample depth. This dependence would generate a refraction index matching effect already observed in other NR structure [25]. However the study of these effects and similar scattering and light trapping mechanism is beyond the scope of present work.

\subsection{Absorption Enhancement}

For further study the differences between CdS and CdTe sensitizers in the absorption enhancement, a figure of merit is introduced and calculated. The Solar Irradiance transmitted through these simulated mixtures $\left(\mathrm{I}_{\mathrm{AM} 1.5}{ }^{\mathrm{T}}\right)$ was calculated from the solar standard total terrestrial irradiance AM 1.5 irradiance spectra $\left(\mathrm{I}_{\mathrm{AM} 1.5}{ }^{0}\right)$ and the calculated transmittance $\left(\mathrm{T}_{\mathbf{j}}\right)$ where $\mathrm{j}=\mathrm{CdS}, \mathrm{CdTe}$ :

$$
I_{A M 1.5}^{T}=T_{J} * I_{A M 1.5}^{0}
$$

In the same way of eq. (2) the irradiance transmitted by the pure $\mathrm{ZnO}$ film $\left(\mathrm{f}_{\mathrm{S}}=0\right)$ is defined as $\mathrm{I}_{\mathrm{AM} 1.5}{ }^{\mathrm{ZnO}}$. Moreover, the total intensity transmitted by the pure $\mathrm{ZnO}$ film $\left(\mathrm{P}^{0}\right)$ and the mixtures $\left(\mathrm{P}^{\mathrm{T}}\right)$ were calculated from:

$$
\begin{aligned}
& P^{T}=\int I_{A M 1.5}^{T}(\lambda) d \lambda \\
& P^{0}=\int I_{A M 1.5}^{Z n O}(\lambda) d \lambda
\end{aligned}
$$

And the Figure of merit $(\mathrm{F})$ is defined as:

$$
F=\frac{\left(P^{0}-P^{T}\right)}{P^{0}}
$$

Eq. (5) shows the definition of the figure of merit as the relative difference between the total power (per square meter) transmitted by the $\mathrm{ZnO}$ NR film and the total power transmitted by the sensitizer mixture. This quantity is an indicator of the enhancement in the absorption capability of the mixture compared with the capability of absorption of the bare $\mathrm{ZnO}$ NR film. Main Figure 3 shows the behaviour of $F$ with $\mathrm{f}_{\mathrm{S}}$ for $\mathrm{CdS}$ (circles) and CdTe (triangles) sensitizers obtained from simulations. For $0 \%$ sensitizer content both mixtures show $0 \%$ enhancement compared with bare $\mathrm{ZnO}$. As the content of sensitizer starts to increase the absorption of the sensitized mixtures starts to grow from the bare $\mathrm{ZnO}$ absorption. Moreover, as $\mathrm{f}_{\mathrm{S}}$ increases the figure of merit for the CdTe sensitizer starts to be higher than the one of CdS even for low $\mathrm{f}_{\mathrm{S}}$ values (i.e. 5 $\%)$. Also, a slowing in the increment rate is observed in both sensitizers for $\mathrm{f}_{\mathrm{S}}$ higher than $40 \%$. In effect, an increment from $80 \%$ to $95 \%$ on $\mathrm{F}$ is observed for an increase in $\mathrm{f}_{\mathrm{S}}$ from $40 \%$ to $100 \%$ in the case of CdTe sensitizer. This saturation like effect on the absorption enhancement indicates an upper threshold for the maximum $\mathrm{f}_{\mathrm{S}}$ which leads to significant improvements in the absorption of the mixture. Moreover it may have a crucial significance in the development of solar cells based in these composite structures avoiding unnecessary waste of sensitizer material. Indeed, the incremental power gain for $\mathrm{f}_{\mathrm{S}}$ higher than $40 \%$ may not justify the cost of additional sensitizer, leading to savings in needed material in eventual final devices.

This saturation like behaviour can be understood due to the exponential dependence of the transmittance with the absorption coefficient $\alpha$, which can be linearized for low absorption. Moreover, for very low sensitizer contents the absorption coefficient depends linearly with $\mathrm{f}_{\mathrm{S}}$ leading to the almost linear behaviour observed in Figure $3\left(\mathrm{f}_{\mathrm{S}}<5 \%\right)$. As the sensitizer content becomes higher the relation between the absorption and $f_{S}$ is no more linear. The saturation like effect on the figure of merit is similar to the behaviour observed for the transmittance when the optical path of the films is increased: the light is mainly absorbed in a region of the order of the penetration depth $1 / \alpha$. Then, this figure of merit is showing an effective enhancement on the optical light path of the samples as the sensitization content is increased.

A similar behaviour is observed in $\mathrm{ZnO} / \mathrm{CdS}$ NR core-shell arrays prepared by spin coating assisted SILAR. The inset of Figure 3 shows the F dependency on the number of sensitization cycles (squares) for this case. The same overall behaviour observed in the simulated mixtures is also observed in these 
experimental measurements. Although it is difficult to associate the number of cycles with the filling factor this interpretation is still possible because is highly expected that an increase in the number of coatings will provide a greater $\mathrm{CdS}$ content in the mixture. Further studies are required to fully understand the nature of the interaction and energy transfer on the $\mathrm{ZnO} /$ sensitizer interfaces. However a significant improvement on the photocurrent is observed on the $\mathrm{ZnO} / \mathrm{CdS} \mathrm{NR}$ array compared with the bare $\mathrm{ZnO}$ photocurrent [7].

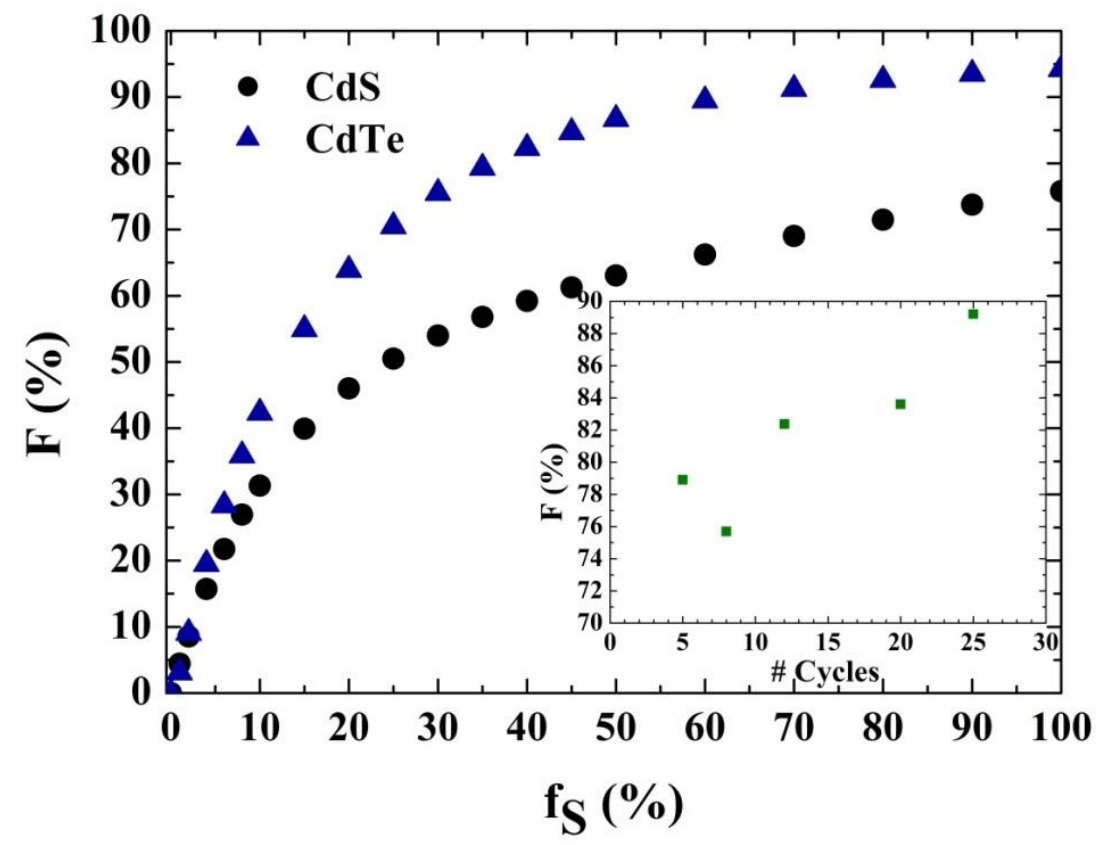

Figure 3: Figure of merit for the absorption enhancement of $\mathrm{ZnO} / \mathrm{CdS}$ mixtures (circles) and $\mathrm{ZnO} / \mathrm{CdTe}$ mixtures (triangles). Inset Figure of merit for spin SILAR sensitized ZnO NR CdTe nanoparticles core-shell array.

\subsection{Absorption Edge red-shift}

In a previous work on previous mentioned spin coating assisted SILAR ZnO/CdS samples a red-shift in the absorption edges positions were reported [ $[\underline{6}, \underline{8}]$. Red-shifts between $2.34 \mathrm{eV}$ and $2.66 \mathrm{eV}$ were observed; an increase in the number of cycles generated a red-shift in CdS absorption edge position [6]. Substantially smaller shifts are observed in the simulated mixtures. Therefore, the experimental shifts cannot be explained by the effective medium approximation so different effects (e.g. subbandgap absorption, dispersions and scattering in the surface or nanostructure) could be responsible for the relative large shifts observed $[\underline{6}, \underline{8}, \underline{26}]$.

In the $\mathrm{ZnO} / \mathrm{CdTe}$ samples as CdTe absorption edge is located ca. $1.55 \mathrm{eV}$ [9-13] the visible transmittance of the samples is very low. Due to this low transmittance its measurement was very difficult, therefore for these samples the study was focused in the interpretation of the Diffuse Reflectance spectra. 


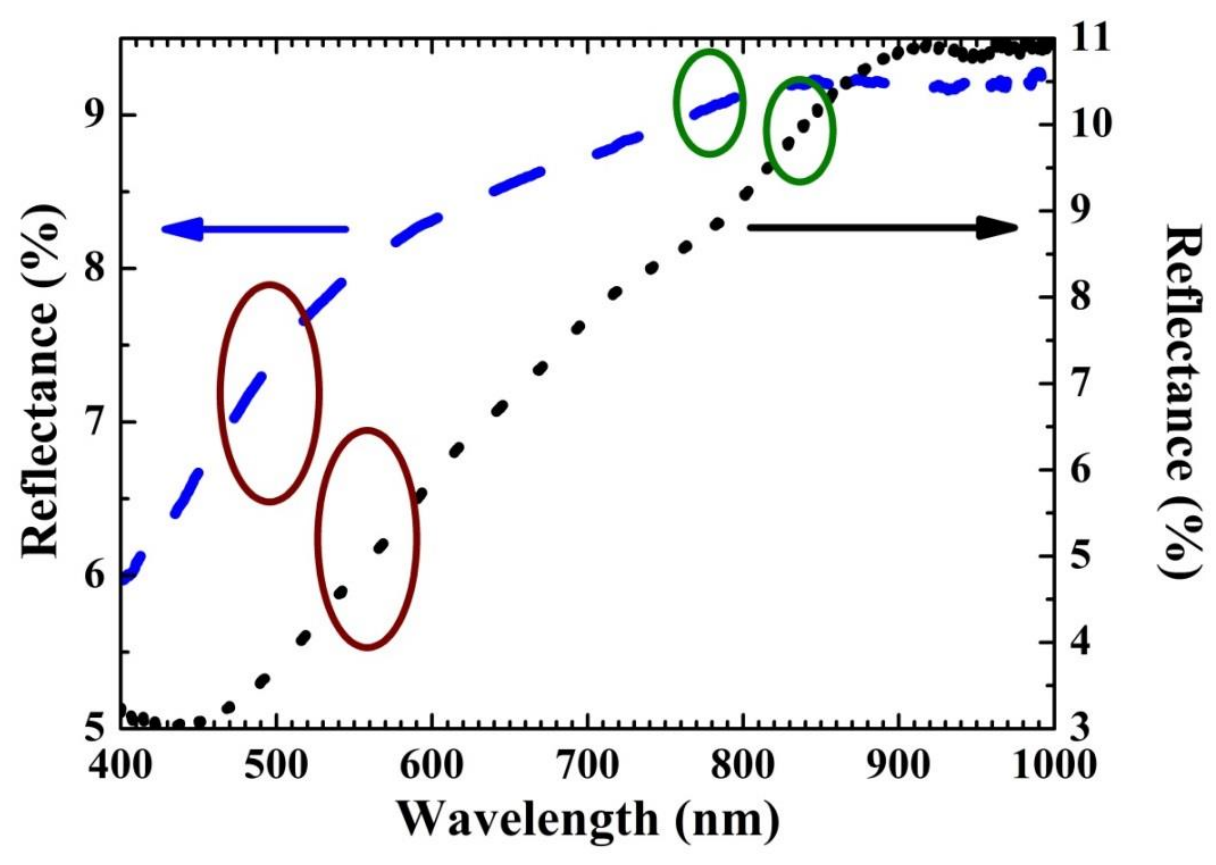

Figure 4: Diffuse Reflectance spectra of $\mathrm{ZnO} / \mathrm{CdTe}$ Sample A (dashed) and sample B (dotted). Red and green circles are the approximated absorption edge positions for CdTe.

Figure 4 shows the diffuse reflectance spectra of two $\mathrm{ZnO} / \mathrm{CdTe}$ core-shell samples the main difference between them is the electrodeposition potential. For sample A (dashed curve) the potential was $-1.1 \mathrm{~V}$ while for sample B (dotted curve) was $-1.2 \mathrm{~V}$. This different potential values indicate a higher content of CdTe in sample B than the one in sample A [19].

For the analysis, the Kubelka-Munk function (FKM) was calculated from the reflectance spectra $\left(\mathrm{R}_{\text {diff }}\right)$. The absorption coefficient was calculated assuming a direct proportionality between FKM and $\alpha[\underline{27}$, $\underline{28]}$.

$$
F_{K M}=\frac{\left(1-R_{\text {diff }}\right)^{2}}{2 R_{\text {diff }}} \propto \alpha
$$

The main differences between the two spectra are the position of the absorption edges (marked with red and green circles respectively in Figure 4. The positions of the absorption edges were calculated using Tauc plots. This approach is based on linear fits of $\left(\alpha^{*} h v\right)^{n}$ vs. $h v$ plots where $n=1 / 2$ for indirect transitions and $\mathrm{n}=2$ for direct allowed transitions [29]. The procedure used in these calculations was performed following the analysis developed in previous works [으- $\underline{8}, \underline{19}, \underline{29}]$.

The low energy (infrared) optical bandgap energy $\mathrm{E}_{\mathrm{g}}{ }^{\mathrm{L}}$ was $1.57 \mathrm{eV}$ and $1.49 \mathrm{eV}$ for samples $\mathrm{A}$ and $\mathrm{B}$ respectively. While for the high energy optical bandgap energy $\mathrm{E}_{\mathrm{g}}{ }^{\mathrm{H}}$ the values obtained were $2.55 \mathrm{eV}$ and $2.28 \mathrm{eV}$ for samples $\mathrm{A}$ and $\mathrm{B}$ respectively. The differences in these values could be associated with the relative higher CdTe content in sample B. Moreover this mayor concentration could be responsible for the high red-shift particularly observed in $\mathrm{E}_{\mathrm{g}}{ }^{\mathrm{H}}$. As the concentration of CdTe is increased subbandgap absorption would be more significant compared with the band edge absorption. Moreover as the CdTe NP cover becomes thicker the surface of the NR arrays increase it roughness leading to an augmented light scattering in the NP as previously observed for CdS NP sensitizer $[\underline{6}, \underline{8}, \underline{26}]$. The combination of these effects produces a subestimation in the value of $\mathrm{E}_{\mathrm{g}}{ }^{\mathrm{H}}$ that is clearly observed in Figure 5. Figure 5 shows the experimental absorption coefficient (circles) plotted with the reconstructed absorption coefficient (continuous curve). The positions of the optical bandgap energies $\left(\mathrm{E}_{\mathrm{g}}{ }^{\mathrm{L}}\right.$ and $\mathrm{E}_{\mathrm{g}}{ }^{\mathrm{H}}$ ) are also marked. The discrepancy between the reconstructed absorption coefficients and the experimental absorption coefficient may be also an indicator of the influence of the subbandgap absorption, although this discrepancy may be due to the band non- 
parabolicity of the low lying absorption edge $\mathrm{E}_{\mathrm{g}}{ }_{\mathrm{L}}$. The reconstructed absorption coefficient was calculated following the successive absorption edge subtraction procedure developed in previous works $[\underline{6}-\underline{8}, \underline{20}]$.

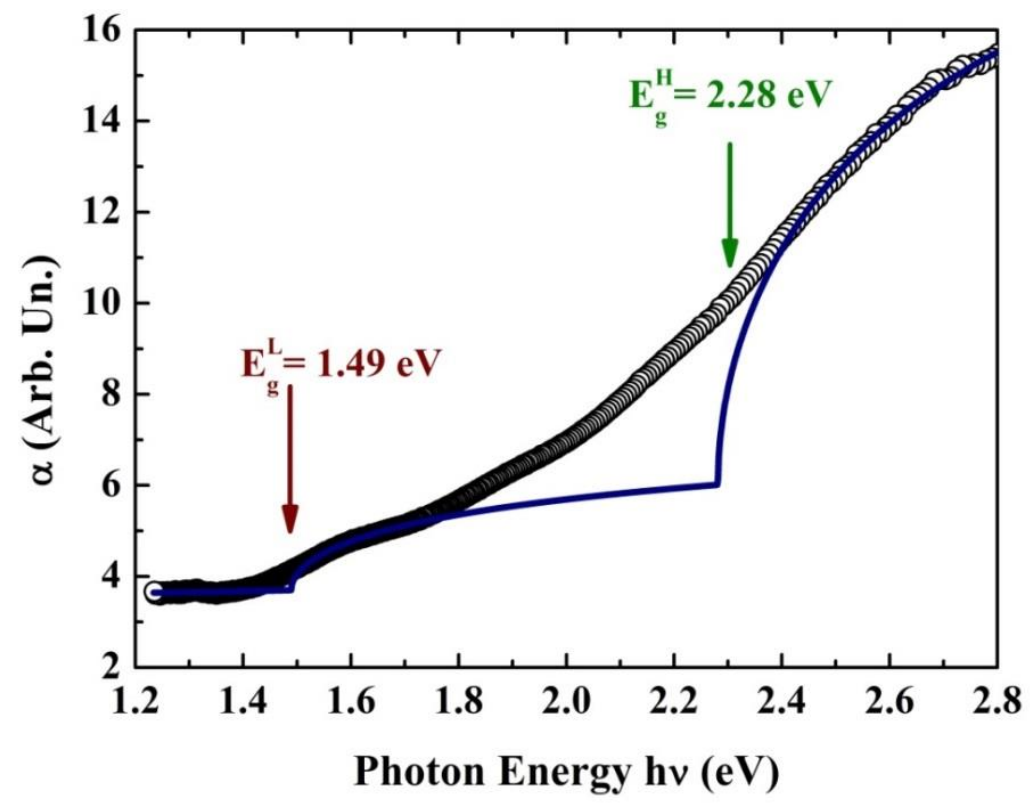

Figure 5: Experimental absorption coefficient of sample B (circles) and reconstructed from the absorption band edge determination absorption coefficient (continuous curve).

The optical bandgap energy obtained from the transmittance measurements (results not shown) were $1.31 \mathrm{eV}$ and $1.36 \mathrm{eV}$ for samples A and B respectively. These energy values, that are lower than the obtained by reflectance, could be explained in terms of the amount of material which interacts with the light beam. Light transmitted through the sample interacts with the full thickness of the sample while reflected light only interact with a thinner one [30]. Then as the interaction with the samples is higher for transmittance measurements a higher red-shift will be observed for transmittance than for the reflectance bandgap energies.

\section{CONCLUSIONS}

The optical properties of CdS and CdTe sensitized ZnO NR core-shell arrays were studied. An absorption enhancement was observed from numerical simulations and experimental results. This enhancement shows a high grown pace (against sensitizer filling factors) for lower sensitizer content and a smaller one when the concentration is high. Also, saturation like behaviour is observed for both mixtures for filling factors higher than $40 \%$. This saturation may lead to important sensitizer saving in potential solar cell devices based in these nanostructures. The $\mathrm{ZnO} / \mathrm{CdTe}$ sensitized mixtures showed the highest rates and also a higher visible absorption than the $\mathrm{ZnO} / \mathrm{CdS}$ mixtures.

Red-shifts in the bandgap energies were observed as a consequence of the sensitization for $\mathrm{ZnO} / \mathrm{CdS}$ samples. Also, similar shifts were observed in $\mathrm{ZnO} / \mathrm{CdTe}$ samples when the same sample was studied by transmittance and reflectance. This is an indicator of the role of dispersions and subbandgap absorption in the bandgap energy position. Both effects are likely to be more significant as the content of sensitizer is increased.

\section{ACKNOWLEDGMENTS}

CSIC (Comisión Sectorial de Investigación Científica) of the Universidad de la República; Comisión Académica de Posgrados of the Universidad de la República ; ANII (Agencia Nacional de Investigación e Innovación); PEDECIBA-Física, in Uruguay. Junta de Andalucía, Project P07-FQM-02573 in Spain.

\section{BIBLIOGRAPHY}

[1] KAYES, B. M., ATWATER, H. A., LEWIS, N. S., "Comparison of the device physics principles of planar and radialn p-n junction nanorod solar cells", J. Appl. Phys. v. 97, n. 114302, pp. 114302-2- 114302- 
11, May 2005.

[2] MUSSELMAN, K. P., WISNET, A., IZA, D. C., et al., "Strong Efficiency Improvements in Ultra-lowCost Inorganic Nanowire Solar Cells", Adv. Mater. v. 22, n. 35, pp. E254- E258, Sep. 2010.

[3] OZQÜR, Ü., ALIVOV, Y. I., LIU, V., et al s “A comprehensive review of ZnO materials and devices”, $J$. Appl. Phys. v. 98, n. 041301, pp. 041301-1-041301-103, Feb. 2005.

[4] FAN, Z., RUEBUSCH, D. J., RATHORE, A. A., et al., "Challenges and Prospects of Nanopillar-Based Solar Cells", Nano Res. v. 2, n. 829, pp. 829-843, Sep. 2009.

[5] YU, R., LIN, Q., LEUNG, S.-F., et al., "Nanomaterials and nanostructures for efficient light absorption and photovoltaics", Nano Energy, v.1, pp. 57-72, Jan. 2012.

[6] CAMPO, L., PEREYRA, C. J., AMY, L., et al., "Electrochemically Grown ZnO Nanorod Arrays Decorated with CdS Quantum Dots by Using a Spin-Coating Assisted Successive-Ionic-Layer-Adsorption and Reaction Method for Solar Cell Applications", ECS J. Solid State Sci. and Technol., v. 2, n. 9, pp. Q151Q158, June 2013.

[7] GUERGUERIAN, G., ELHORDOY, F., PEREYRA, et al., "ZnO nanorod/CdS nanocrystal core/shelltype heterostructures for solar cell applications", Nanotechnology, v. 22, n. 505401, pp.1-9, Nov. 2011.

[8] Pereyra, C. J., MAROTTI, R. E., GUERGUerian, G., et al., "Optical Properties of Electrochemically Prepared Zinc Oxide Nanorods", Energy Environ. Focus, v. 2, n. 4, pp. 257-269, Dec. 2013.

[9] KHAN, Z. R., ZULFEQUAR, M., KHAN, M. S., "Structural, optical, photoluminescence, dielectric and electrical studies of vacuum-evaporated CdTe thin films", Bull. Matter. Sci. v. 35,n. 2, pp. 169-174, April 2012.

[10] LALITHA, S., KARAZHZNOV, S. ZH., RAVINDRAN, P., et al., "Electronic structure, structural and optical properties of thermally evaporated CdTe thin films", Physica B., v. 387, pp. 227-238, Jan. 2007.

[11] AL-DOURI, A. A. J., AL-SHAKILY, F. Y., ALIAS, M. F. A., et al., "Optical Properties of Al- and SbDoped CdTe Thin Films," Advances in Condensed Matter Physics, v. 2010, n. 947684, pp. 1-5, Jan 2010

[12] ADACHI, S., KIMURA, T., SUZUKI, N., "Optical properties of CdTe: Experiment and modeling", J. Appl. Phys., v. 74, n. 3435, pp. 3435-3441, Jun. 1993.

[13] PAULSON P. D., MATHEW, X., "Spectroscopic ellipsometry investigation of optical and interface properties of CdTe films deposited on metal foils", Sol. Ener. Mat. Sol. Cells, v. 82, n. 1, pp. 279-290, May 2004.

[14] NILES, D. W., HÖCHST, H., "Critical test of CdTe(100) angle-resolved photoemission spectra with band-structure calculations", Phys Rev. B, v. 43 n. 2, pp. 1492-1499, Jan. 1991.

[15] BOJORGE, C. D., KENT, V. R.,TELIZ, E., et al., "Zinc-oxide nanowires electrochemically grown onto sol-gel spin-coated seed layers", Phys. Status Solidi A, v.208, n. 7, pp. 1662-1669, July 2011.

[16] STENZEL, O., The Physics of Thin Film Optical Spectra - An Introduction., 1 Ed., Berlin, SpringerVerlag, 2005.

[17] LIU, Y. C., TUNG, S. K.., HSIEK, J. H., "Influence of annealing on optical properties and surface structure of ZnO thin films", J. Cryst. Growth. v. 287, n. 1, pp. 105-111, Jan. 2006.

[18] NIMONIYA, S., ADACHI, S., "Optical properties of wurtzite CdS ", J. Appl. Phys. v. 78, pp. 11831190, March 1995.

[19] NICHELATTI, E., "Complex refractive index of a slab from reflectance and transmittance: analytical solution", J. Opt. A: Pure Appl. Opt., v. 4, pp.400-403, May 2002.

[20] GUERGUERIAN, G., ELHORDOY, F., PEREYRA C. J., "ZnO/Cu2O heterostructure nanopillar arrays: synthesis, structural and optical properties", J. Phys. D: Appl. Phys. v. 45, n. 245301, pp. 1-10, May 2012.

[21] NIKLASSON G. A., GRANQVIST, C. G., HUNDERI, O. "Effective médium model for the optical properties of inhomogeneous materials", Appl. Opt., v. 22, n.1, pp. 26-30, 1981

[22] BOJORGE, C. D.; KENT, V. R., TELIZ, E., et al.,"Zinc Oxide Nanowires Electrochemically Grown onto Sol-Gel Spin Coated Seed Layers", Physica Status Solidi A, v. 208, n.7, pp.1662-1669, 2011 (doi:10.1002/pssa.201026752)

[23] PEREYRA, C. J., MAROTTI, R. E., GUERGUERIAN, G., et al.,“Optical Properties of Sensitized Zinc Oxide Nanorods Electrochemically Prepared”, Energy and Environment Focus, v.2, n.4, pp.257-269, 2013. (dx.doi.org/10.1166/eef.2013.1061) 
[24] DAVOINE, F. ., GALIONE, P. A., RAMOS-BARRADO, J. R., et al.,"Modeling of gradient index solar selective surfaces for solar thermal applications", Solar Energy, v. 91, pp. 316-326, 2013. (DOI: 10.1016/j.solener.2012.09.019)

[25] BADÁN, J. A., MAROTTI, R. E., DALChiEle, E. A., et al.,“Optical Properties of Si Nanowires: Dependence with Substrate Crystallographic Orientation and Light Polarization", Journal of Materials Research, doi 10.1557/jmr.2015.47

[26] RABINOVICH, E., HODES, G., "Effective Bandgap Lowering of CdS Deposited by Successive Ionic Layer Adsorption and Reaction", J. Phys. Chem. C., v. 117, n. 4, pp. 1611-1620, Jan. 2013.

[27] TORRENT, J., BARRÓN, V., Encyclopedia of Surface and Colloid Science, edited by Hubbard, A. T., 2 ed., New York, CRC Press, 2002.

[28] SCHRÖDERAND, U., SCHOLZ, F., "Microscopic in situ diffuse reflectance spectroelectrochemistry of solid state electrochemical reactions of particles immobilized on electrodes", J. Solid State Electrochem. v. 1, n. 1, pp.62-67, July 1997.

[29] KIM, E., JIANG, Z.T., NO, K., "Measurement and calculation of optical band gap of chromium aluminum oxide films", J. Appl. Phys., v.39, n.8, 2000.

[30] JOHNSON, S. R., TIEDJE, T., "Temperature Dependence of the Urbach edge in GaAs", J. Appl. Phys. v. 78, n. 9, pp. 5609-5613, Jun. 1995. 